\title{
Comparison between cisplatin plus vinorelbine and cisplatin plus docetaxel in the treatment of advanced non-small-cell lung cancer: A meta-analysis of randomized controlled trials
}

\author{
GUODONG SHEN $^{1,2}$, GENG BIAN ${ }^{2}$, HAIYING YU ${ }^{2}$, MIN GAO $^{1}$, DONGMEI KANG ${ }^{1}$, \\ GAN SHEN $^{1,2}$ and SHILIAN HU ${ }^{1,2}$ \\ ${ }^{1}$ Geriatrics Department, Anhui Provincial Hospital; \\ ${ }^{2}$ Anhui Provincial Key Laboratory of Tumor Immunotherapy and Nutrition Therapy, Hefei, Anhui 230001, P.R. China
}

Received July 2, 2013; Accepted October 14, 2013

DOI: $10.3892 / \mathrm{mco} .2013 .210$

\begin{abstract}
Whether cisplatin plus vinorelbine (VC) or cisplatin plus docetaxel (DC) are equally effective in the treatment of advanced non-small-cell lung cancer (NSCLC) remains controversial. The aim of this study was to compare the $\mathrm{VC}$ and DC regimens in the first-line treatment of advanced NSCLC. A search was conducted through PubMed, the Cochrane Central Register of Controlled Trials (CENTRAL), EMBASE and the Chinese Biomedical Literature database (CBM). The language of the publication was not considered to be a limitation. The recruited trials were evaluated for eligibility and quality and the data were extracted and analyzed. The endpoints were overall response, survival rate and toxicity. We analyzed 9 randomized controlled trials (RCTs), including a total of 1,886 patients. Patients receiving DC therapy exhibited a significantly higher response rate [relative risk $(R R)=0.83$, 95\% CI: $0.73-0.95$ and $\mathrm{P}=0.007$ ] and 2-year survival rate ( $R R=0.65,95 \%$ CI: $0.50-0.84$ and $\mathrm{P}=0.001$ ). However, the 1 -year survival rate for the two cisplatin-based regimens were comparable ( $\mathrm{RR}=0.90,95 \% \mathrm{CI}: 0.81-1.01$ and $\mathrm{P}=0.07$ ). Patients receiving the $\mathrm{VC}$ regimen more frequently developed grade 3/4 leucopenia, anemia and vomiting, whereas those receiving DC chemotherapy were more prone to grade $3 / 4$ diarrhea. The incidence of grade $3 / 4$ neutropenia, thrombocytopenia and nausea were similar between the two arms. In conclusion, our study indicated that DC is superior to the VC regimen in terms of tumor response rate, 2-year survival rate and safety for the first-line treatment of advanced NSCLC.
\end{abstract}

\footnotetext{
Correspondence to: Professor Shilian Hu, Geriatrics Department, Anhui Provincial Hospital, 17 Lujiang Road, Hefei, Anhui 230001, P.R. China

E-mail: hushilian@126.com
}

Key words: non-small-cell lung cancer, vinorelbine, docetaxel, cisplatin, meta-analysis

\section{Introduction}

Lung cancer is the leading cause of cancer-related mortality, resulting in over one million deaths annually worldwide (1). Non-small-cell lung cancer (NSCLC) accounts for $>80 \%$ of lung cancer cases. However, approximately two-thirds of patients have inoperable locally advanced (stage IIIB) or metastatic (stage IV) disease at the time of diagnosis, with a 1 -year survival rate of $<20 \%(2,3)$. It was demonstrated that the integrated basic treatment with chemotherapy is crucial in advanced NSCLC. Platinum-based doublet regimens are considered to be the standard treatment for advanced NSCLC (4-7). With the development of third-generation cytotoxic agents, such as taxanes, gemcitabine and vinorelbine, doublet chemotherapies consisting of platinum plus a third-generation agent are currently considered to be the standard regimens and are recommended as first-line chemotherapy for advanced NSCLC by the American Society of Clinical Oncology (ASCO) and the National Comprehensive Cancer Net $(5,8,9)$. Vinorelbine was the first agent to demonstrate a survival benefit when combined with cisplatin and it consequently became a standard regimen for the first-line treatment of NSCLC (10). Docetaxel was the first drug approved for the second-line treatment of NSCLC (5). Docetaxel plus cisplatin (DC) treatment was shown to have better survival benefits compared with vinorelbine plus cisplatin (VC) treatment (11) and may therefore be used as a first-line agent in combination with platinum. Although third-generation anticancer drugs in combination with cisplatin may have the best efficacy in terms of longer survival and milder toxicity profiles, their use is currently controversial $(5,12)$. Consequently, we conducted a systemic overview on published phase II and III randomized controlled trials (RCTs) comparing VC and DC in the first-line treatment of advanced NSCLC, with study endpoints such as tumor response rate, overall survival and toxicity.

\section{Materials and methods}

Search strategy. An electronic search was conducted through PubMed, the Cochrane Central Register of Controlled Trials (CENTRAL), EMBASE and the Chinese Biomedical 
Table I. Baseline characteristics of the 9 trials comparing VC with DC in the treatment of advanced non-small-cell lung cancer.

\begin{tabular}{|c|c|c|c|c|c|}
\hline $\begin{array}{l}\text { Patient } \\
\text { no. }\end{array}$ & Treatment regimen & $\begin{array}{c}\text { Mean } \\
\text { age (years) }\end{array}$ & $\begin{array}{c}\text { Disease stage } \\
(\% \text { IIIB/IV })\end{array}$ & $\begin{array}{l}\text { Quality } \\
\text { scores }\end{array}$ & Year (refs.) \\
\hline 404 & Vin $25 \mathrm{mg} / \mathrm{m}^{2} \mathrm{~d} 1,8,15$ and $22+\operatorname{cispl} 100 \mathrm{mg} / \mathrm{m}^{2} \mathrm{~d} 1^{\mathrm{a}}$ & 61 & $33 / 67$ & 3 & $2003(11)$ \\
\hline 408 & Doc $75 \mathrm{mg} / \mathrm{m}^{2} \mathrm{~d} 1+\operatorname{cispl} 75 \mathrm{mg} / \mathrm{m}^{2} \mathrm{~d} 1$ & 61 & $33 / 67$ & & \\
\hline 118 & Vin $30 \mathrm{mg} / \mathrm{m}^{2} \mathrm{~d} 1,8+\operatorname{cispl} 100 \mathrm{mg} / \mathrm{m}^{2} \mathrm{~d} 1$ & 57 & $0 / 100$ & 3 & $2005(15)$ \\
\hline 115 & Doc $75 \mathrm{mg} / \mathrm{m}^{2} \mathrm{~d} 1+\operatorname{cispl} 100 \mathrm{mg} / \mathrm{m}^{2} \mathrm{~d} 1$ & 58 & $0 / 100$ & & \\
\hline 33 & Vin $25 \mathrm{mg} / \mathrm{m}^{2} \mathrm{~d} 1,8+\operatorname{cispl} 20 \mathrm{mg} / \mathrm{m}^{2} \mathrm{~d} 1-3$ & 56 & $46 / 54$ & 2 & $2006(16)$ \\
\hline 26 & Doc $37.5 \mathrm{mg} / \mathrm{m}^{2} \mathrm{~d} 1,8+\operatorname{cispl} 20 \mathrm{mg} / \mathrm{m}^{2} \mathrm{~d} 1-3$ & 55 & $27 / 73$ & & \\
\hline 48 & Vin $25 \mathrm{mg} / \mathrm{m}^{2} \mathrm{~d} 1,8+\operatorname{cispl} 60 \mathrm{mg} / \mathrm{m}^{2} \mathrm{~d} 1$ & 65 & $17 / 83$ & 3 & 2007 (17) \\
\hline 46 & Doc $160 \mathrm{mg} / \mathrm{m}^{2} \mathrm{~d} 1+\operatorname{cispl} 60 \mathrm{mg} / \mathrm{m}^{2} \mathrm{~d} 1$ & 60 & $20 / 80$ & & \\
\hline 45 & Vin $30 \mathrm{mg} / \mathrm{m}^{2} \mathrm{~d} 1,8+\operatorname{cispl} 25 \mathrm{mg} / \mathrm{m}^{2} \mathrm{~d} 1-3$ & 51 & $58 / 42$ & 3 & $2007(18)$ \\
\hline 42 & Doc $75 \mathrm{mg} / \mathrm{m}^{2} \mathrm{~d} 1+\operatorname{cispl} 30 \mathrm{mg} / \mathrm{m}^{2} \mathrm{~d} 1-3$ & 47 & $60 / 40$ & & \\
\hline 33 & Vin $25 \mathrm{mg} / \mathrm{m}^{2} \mathrm{~d} 1,8+\operatorname{cispl} 75 \mathrm{mg} / \mathrm{m}^{2} \mathrm{~d} 1$ & - & $55 / 45$ & 2 & 2007 (19) \\
\hline 34 & Doc $75 \mathrm{mg} / \mathrm{m}^{2} \mathrm{~d} 1+\operatorname{cispl} 75 \mathrm{mg} / \mathrm{m}^{2} \mathrm{~d} 1$ & - & $59 / 41$ & & \\
\hline 35 & Vin $25 \mathrm{mg} / \mathrm{m}^{2} \mathrm{~d} 1,8+\operatorname{cispl} 27 \mathrm{mg} / \mathrm{m}^{2} \mathrm{~d} 1-3$ & 62 & $63 / 37$ & 2 & $2007(20)$ \\
\hline 32 & Doc $37.5 \mathrm{mg} / \mathrm{m}^{2} \mathrm{~d} 1,8+\operatorname{cispl} 27 \mathrm{mg} / \mathrm{m}^{2} \mathrm{~d} 1-3$ & 61 & $63 / 37$ & & \\
\hline 190 & Vin $30 \mathrm{mg} / \mathrm{m}^{2} \mathrm{~d}$ 1iv, $80 \mathrm{mg} / \mathrm{m}^{2} \mathrm{~d} 8$ oral + cispl $80 \mathrm{mg} / \mathrm{m}^{2} \mathrm{~d} 1$ & 59 & $20 / 80$ & 3 & $2009(21)$ \\
\hline 191 & Doc $75 \mathrm{mg} / \mathrm{m}^{2} \mathrm{~d} 1+\operatorname{cispl} 75 \mathrm{mg} / \mathrm{m}^{2} \mathrm{~d} 1$ & 62 & $15 / 85$ & & \\
\hline 44 & Vin $30 \mathrm{mg} / \mathrm{m}^{2} \mathrm{~d} 1,8+\operatorname{cispl} 80 \mathrm{mg} / \mathrm{m}^{2} \mathrm{~d} 1$ & 62 & $20 / 80$ & 2 & $2009(22)$ \\
\hline 42 & Doc $75 \mathrm{mg} / \mathrm{m}^{2} \mathrm{~d} 1+\operatorname{cispl} 75 \mathrm{mg} / \mathrm{m}^{2} \mathrm{~d} 1$ & 61 & $19 / 81$ & & \\
\hline
\end{tabular}

a28 days per cycle; the remaining, 21 days per cycle. Vin, vinorelbin; doc, docetaxel; cispl, cisplatin; VC, vinorelbine plus cisplatin; DC, docetaxel plus cisplatin; yrs, years; d, day; iv, intravenous.

Literature database (CBM) up to May, 2013, for trials comparing $\mathrm{VC}$ to $\mathrm{DC}$ in the management of advanced NSCLC. The following terms were used: 'non-small-cell lung cancer', 'carcinoma, non-small-cell lung', 'chemotherapy' and 'randomized controlled trials'. The language of the publication and year of publication were not considered to be limitations. The reference lists of the original and review articles were also investigated for additional literature.

Inclusion criteria. Studies were considered eligible if they compared VC to DC chemotherapy for advanced NSCLC. The patients involved were required to have pathological or cytological confirmation of advanced (stage IIIB/IV) NSCLC, with a performance status of 0-2 on the World Health Organization (WHO) scale, or a Karnofsky performance status of $\geq 80 \%$. Only the full-published studies (RCTs) were selected, whereas conference or meeting abstracts were excluded. The quality of the trials was assessed using the three-question instrument described by Jadad et al (13). The quality scores are listed in Table I.

Data extraction. The following information was independently extracted: first author, year of publication, quality scores, number of patients, chemotherapy regimens, mean age, percentage of stage IIIB and IV disease, overall RR, 1- and 2-year survival and specific toxicity data, such as leucopenia, neutropenia, thrombocytopenia, anemia, nausea and vomiting and diarrhea. Disagreements were resolved through discussion with an independent expert. The characteristics of the meta-analysis for each treatment group were assessed as follows: overall response rate, overall 1- and 2-year survival and number of patients with grade $3 / 4$ specific toxicity data, such as leucopenia, neutropenia, thrombocytopenia, anemia, nausea and vomiting and diarrhea. Since they are considered milestones in survival result analyses of NSCLC chemotherapy, 1- and 2-year survival were selected as primary endpoints. An attempt was made to contact the authors of each unpublished study on whether there had been any update of the trial following its presentation. The response was evaluated according to the Response Evaluation Criteria in Solid Tumors (14) or the WHO criteria and classified as complete response (CR), partial response (PR), stable disease and progressive disease. Overall response was defined as the sum of CR and PR. Toxicity profiles were graded according to the National Cancer Institute Common Toxicity Criteria or the WHO criteria.

Statistical analysis. The analyses were tested by pairwise comparisons between the VC arm of the identified trials and the respective DC arm. The relative risk (RR) for overall response to treatment, 1- and 2-year survival and the odds ratio (OR) for different types of toxicity were calculated using Review Manager software, version 5.0.3 (The Cochrane Collection, Oxford, UK). $\mathrm{P}<0.05$ was considered to indicate a statistically significant difference. An RR of $>1$ reflected a favorable outcome in the $\mathrm{VC}$ arm regarding response and 1- or 2-year survival rate; an OR of $>1$ indicated a higher toxicity in the VC arm. The heterogeneity of the studies was also assessed and $\mathrm{P}<0.1$ was defined as heterogenous. If the test indicated heterogeneity across studies, the random effects 
Table II. Summary of grade 3/4 toxicities in VC and DC for advanced non-small-cell lung cancer.

\begin{tabular}{|c|c|c|c|c|c|c|c|}
\hline \multirow[b]{2}{*}{ Toxicity } & \multirow[b]{2}{*}{ No. of studies } & \multicolumn{2}{|c|}{ No. of cases } & \multicolumn{2}{|c|}{ Test of homogeneity } & \multirow[b]{2}{*}{ OR $(95 \% \mathrm{CI})$} & \multirow[b]{2}{*}{ P-value } \\
\hline & & $\mathrm{VC}$ & $\mathrm{DC}$ & $\mathrm{I}^{2}(\%)$ & P-value & & \\
\hline Leucopenia & 8 & $338 / 822$ & $298 / 817$ & 21 & 0.26 & $1.26(1.02,1.54)^{\mathrm{a}}$ & 0.03 \\
\hline Neutropenia & 6 & $561 / 829$ & $524 / 830$ & 65 & 0.01 & $1.46(0.93,2.29)^{\mathrm{b}}$ & 0.10 \\
\hline Thrombocytopenia & 8 & $33 / 907$ & $19 / 898$ & 0 & 0.88 & $1.69(0.97,2.96)^{\mathrm{a}}$ & 0.06 \\
\hline Anemia & 6 & $146 / 686$ & $51 / 683$ & 48 & 0.09 & $3.40(2.42,4.76)^{\mathrm{a}}$ & $<0.0001$ \\
\hline Nausea & 4 & $88 / 752$ & $72 / 758$ & 77 & 0.004 & $0.94(0.37,2.38)^{\mathrm{b}}$ & 0.90 \\
\hline Vomiting & 6 & $99 / 831$ & $66 / 832$ & 47 & 0.10 & $1.58(1.14,2.20)^{\mathrm{a}}$ & 0.006 \\
\hline Diarrhea & 6 & $15 / 829$ & $49 / 826$ & 0 & 0.71 & $0.31(0.18,0.55)^{\mathrm{a}}$ & $<0.0001$ \\
\hline
\end{tabular}

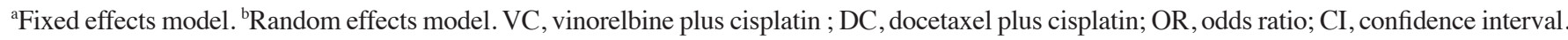

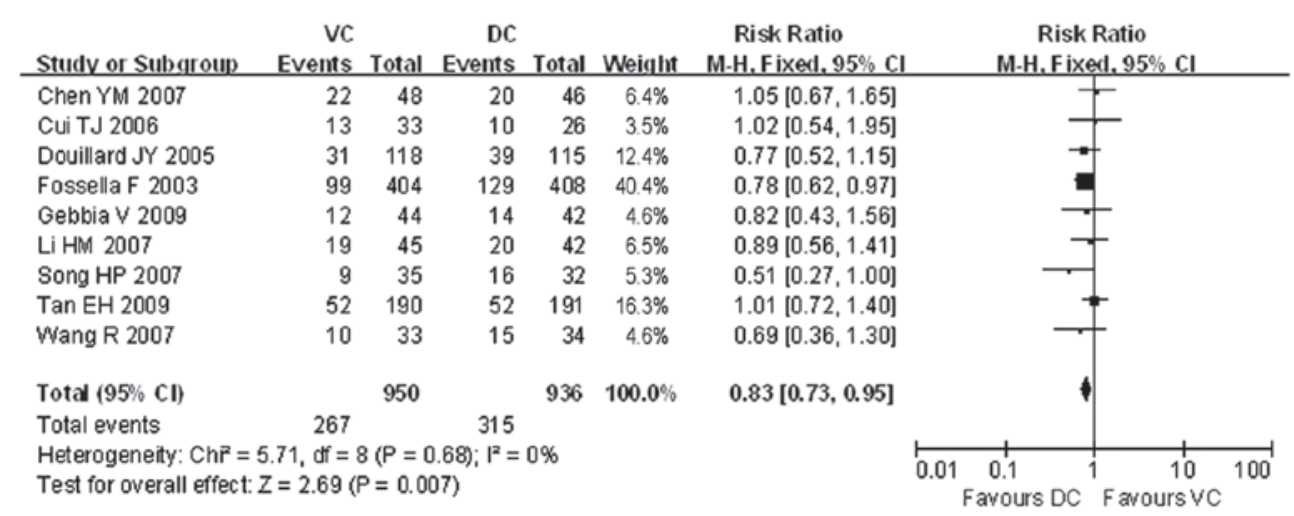

Figure 1. The overall response rate analysis of vinorelbine plus cisplatin (VC) or docetaxel plus cisplatin (DC) for advanced non-small-cell lung cancer (NSCLC). The fixed effects model was applied. Relative risk (RR) ratio and $95 \%$ confidence interval (CI) for each study are also plotted on the graph.

model (Der Simonian and Laird) was selected. Otherwise, we used the fixed effects model (Mantel-Haenszel) to analyze two treatment groups. All toxicities were analyzed in the trials stating the relative toxicities in a per-patient manner; trials not reporting on the relative toxic effects or reporting in a different way (e.g., reporting toxicities per treatment cycle) were excluded from the toxic effects evaluation.

\section{Results}

Characteristics of the included trials. A total of 9 RCTs that met the inclusion criteria were selected $(11,15-22)$, of which 7 trials were phase II $(15-20,22)$ and the remaining were phase III RCTs $(11,21)$. The details of these trials are summarized in Table I. Randomization was stated in all trials; however, only 5 described the detailed methods of randomization. None of the trials were double-blind and all trials reported withdrawals and drop-outs. Overall, 1,886 patients were randomized to receive VC or DC chemotherapy (950 and 936 patients, respectively).

Response rate. The number of the cases achieving an overall response was presented in all the trials. The intention-to-treat analysis demonstrated that the overall response rate of the VC group was $28.11 \%$ and that of the DC group was $33.65 \%$. The patients receiving DC therapy exhibited a significantly higher response rate $(\mathrm{RR}=0.83,95 \% \mathrm{CI}: 0.73-0.95$ and $\mathrm{P}<0.05)$ (Fig. 1). There was no heterogeneity between the compared groups $\left(\chi^{2}=5.71 ; \mathrm{P}=0.68 ; \mathrm{I}^{2}=0 \%\right)$.

Survival. One-year survival data were available for 7 of the 9 trials (11,17-21), including a total of 1,741 patients (Fig. 2). The 1-year survival rates of the VC and DC group were comparable $(\mathrm{RR}=0.90,95 \% \mathrm{CI}: 0.81-1.01$ and $\mathrm{P}=0.07)$ and there was no heterogeneity $\left(\chi^{2}=2.08 ; \mathrm{P}=0.91 ; \mathrm{I}^{2}=0 \%\right)$. Furthermore, as shown in Fig. 2, patients treated with the DC regimen benefited from a significant reduction in the risk of mortality within the first 2 years $(\mathrm{RR}=0.65,95 \% \mathrm{CI}$ : $0.50-0.84$ and $\mathrm{P}=0.001)$, as shown in the 2 -year survival analysis of 4 trials $(11,15,19,20)$.

Toxicity. All trials provided toxicity profile results. The adverse effects of chemotherapy were described as number of cases experiencing grade 3/4 toxicity. The most frequently reported toxicities included leucopenia, neutropenia, thrombocytopenia, anemia, nausea and vomiting and diarrhea (Table II). VC chemotherapy was more frequently associated with grade 3/4 leucopenia, anemia and vomiting $(\mathrm{OR}=1.26$, 95\% CI: $1.02-1.54$ and $\mathrm{P}<0.05 ; \mathrm{OR}=3.40 ; 95 \% \mathrm{CI}: 2.42-4.76$ and $\mathrm{P}<0.05$; and $\mathrm{OR}=1.58$, 95\% CI: $1.14-2.20$ and $\mathrm{P}<0.05$, respectively), whereas patients receiving DC chemotherapy were more prone to grade $3 / 4$ diarrhea $(\mathrm{OR}=0.31,95 \% \mathrm{CI}$ : $0.18-0.55$ and $\mathrm{P}<0.0001)$. However, the incidence of neutropenia, 


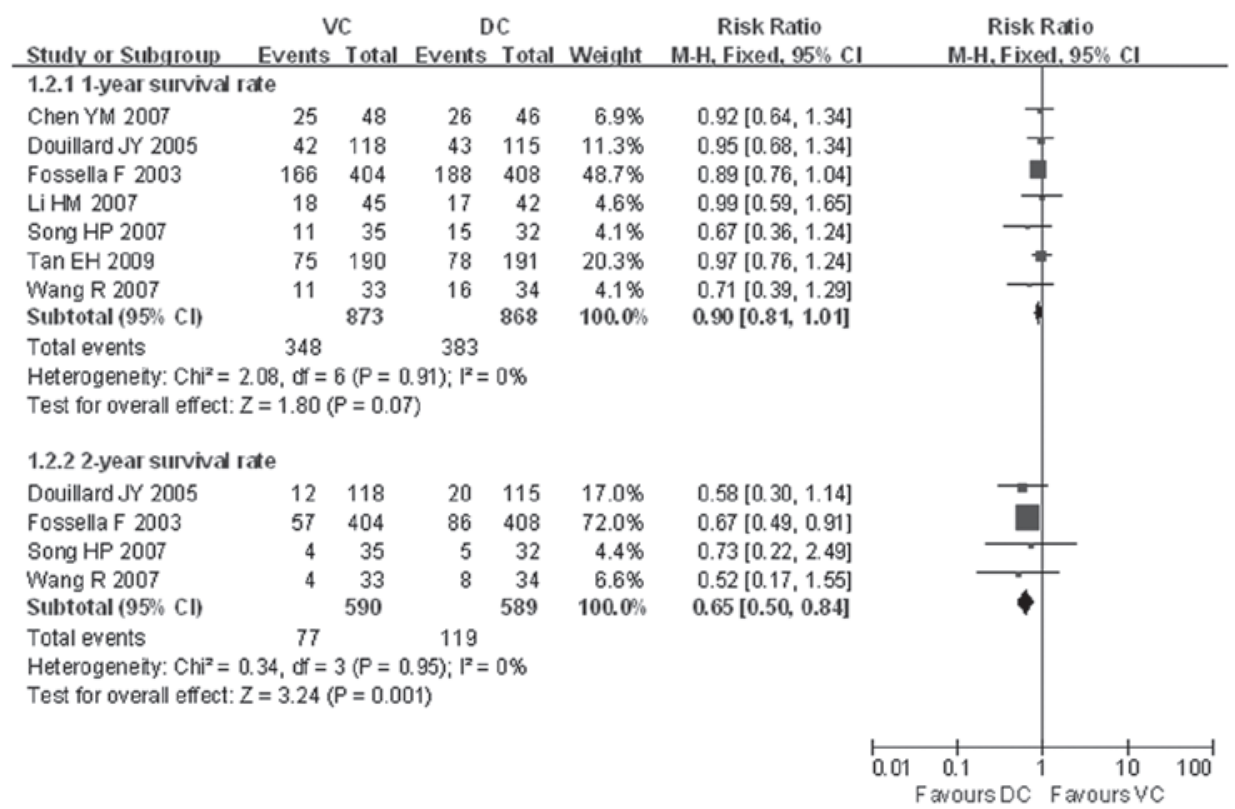

Figure 2. The 1- and 2-year survival analysis of vinorelbine plus cisplatin (VC) or docetaxel plus cisplatin (DC) for advanced non-small-cell lung cancer (NSCLC). The fixed effects model was applied. Relative risk (RR) ratio and 95\% confidence interval (CI) for each study are also plotted on the graph.

thrombocytopenia and nausea were not significantly different between the two groups $(\mathrm{OR}=1.46,95 \% \mathrm{CI}: 0.93-2.29$ and $\mathrm{P}=0.10 ; \mathrm{OR}=1.69,95 \% \mathrm{CI}: 0.97-2.96$ and $\mathrm{P}=0.06$; and $\mathrm{OR}=0.94$; 95\% CI: $0.37-2.38$ and $\mathrm{P}=0.90$, respectively).

\section{Discussion}

NSCLC is a highly malignant disease exhibiting short survival times in the advanced stages. Improving the treatment for advanced NSCLC has proven to be challenging. Several NSCLC meta-analyses have been published over the last decade $(6,23,24)$. These studies helped to determine a doublet chemotherapy consisting of platinum plus a third-generation agent as the gold standard in the treatment of NSCLC $(5,6,8,9,12)$. In this study, we evaluated agents considered to be the gold standard according to current ASCO guidelines and may therefore be clinically useful in selecting the appropriate treatment for patients with advanced NSCLC.

We observed that patients receiving DC therapy exhibited higher response and 2-year survival rates compared to those who received VC therapy; however there was no significant difference in the 1-year survival rate between the VC and DC groups. Since second-line treatment may affect survival, the unbalanced post-study treatment may have had an impact on the survival analysis of our study. We also observed that VC as well as DC may cause hematological and digestive adverse events, although the VC group was prone to develop leucopenia, anemia and vomiting, whereas the DC group was more likely to develop severe diarrhea. There were no significant differences in the incidence of neutropenia, thrombocytopenia and nausea between the two groups.

One of the major issues with the available data on treatment for advanced NSCLC is the lack of quality of life (QoL) analyses. Although 4 trials in this meta-analysis included a formal QoL assessment, the assessment scales used, including
EuroQoL Five-Dimensional Questionnaire (11), Lung Cancer Symptom Scale $(11,17,21)$ and EORTC QLQ-C30 (22), were different; therefore, the data could not be pooled. The QoL scores were not significantly different between the two groups in any of the trials, although the TAX 326 study demonstrated that the DC regimen relieved the symptoms and improved QoL compared to the VC regimen, according to the EuroQoL Five-Dimensional Questionnaire. Since the primary role of chemotherapy in patients with advanced NSCLC is palliative, the effect on patients' QoL is crucial in determining the overall value of new therapy.

Although there is no evidence that the DC regimen improves QoL compared to the VC regimen, our meta-analysis demonstrated that the DC regimen exhibits certain advantages over the VC regimen as first-line treatment for advanced NSCLC. The DC regimen was also associated with a more favorable safety profile compared to the $\mathrm{VC}$ regimen. These findings may be helpful when selecting the appropriate treatment for advanced NSCLC, with the aim of improving the response and survival rates, without increasing toxicity. Recently, with the advances in the research of cancer cell signal transduction, molecular targeted therapy has emerged as a treatment option; such regimens may provide a potential platform on which to add targeted therapy for first-line treatment in the future. Lynch et al (25) performed a phase III trial including 676 patients with advanced NSCLC without restrictions posed by histology or epidermal growth factor receptor expression, in which treatment with taxane plus carboplatin alone was compared to taxane plus carboplatin with cetuximab, confirming a remarkable increase in the overall response rate in taxane plus carboplatin with cetuximab over taxane plus carboplatin alone. The difference in overall survival favored cetuximab, although it did not reach a statistical significance. The results of that study cannot be applied to all patients with advanced NSCLC, as it excluded patients with previous 
infusion reactions to chimerized/murine monoclonal antibodies, history of acute myocardial infarction, higher than grade 2 peripheral neuropathy and inadequate hematological, hepatic or renal functions. However, such patients represent a substantial population of patients with advanced NSCLC and viable alternatives are required to improve their treatment.

This meta-analysis had certain limitations that should be considered. Our study was limited by the number and quality of the available RCTs. Although it may be difficult for phase II studies to produce reliable survival data, no significant heterogeneity was observed in the response rate or in the 1- and 2-year survival rates among the trials included in the analysis. This result of the 2-year survival analysis supports the decision to include all randomized phase II or III trials with prospectively recorded 2-year survival data. Furthermore, the survival data at 2 years of follow-up and some adverse effects were lacking in several trials, which may have led to a biased estimate.

In conclusion, this meta-analysis revealed that DC therapy exhibited a marginally better response rate and 2-year survival rate and a milder toxicity profile compared to VC. Therefore, the former may be the better choice for patients with advanced NSCLC. However, these results need to be interpreted with caution, as the outcome of these meta-analyses on the basis of summary data derived from the literature may be affected by several biases.

\section{Acknowledgements}

This study was funded by the National Natural Science Foundation of China (no. 81071808), the Anhui Provincial Key Science and Technology Project (no. 12010402126), the Natural Science Foundation of Anhui Higher Education Institutions of China (no. KJ2012A284) and the Anhui Provincial Program for Industry Innovative Research Team of Cancer Immunotherapy and Nutrition Diagnosis and Therapy.

\section{References}

1. Parkin DM, Bray FJ and Pisani P: Global cancer statistics, 2002. CA Cancer J Clin 55: 74-108, 2005.

2. DeVita VT, Lawrence TS and Rosenberg SA (eds): DeVita, Hellman, and Rosenberg's Cancer: Principles and Practice of Oncology, 9th Edition. Lippincott Williams \& Wilkins, Philadelphia, 2009.

3. Montazeri A, Gillis CR and McEwen J: Quality of life in patients with lung cancer: a review of literature from 1970 to 1995. Chest 113: 467-481, 1998.

4. Abratt RP and Hart GJ: 10-year update on chemotherapy for non-small cell lung cancer. Ann Oncol 17 (Suppl 5): v33-v36, 2006.

5. Pfister DG, Johnson DH, Azzoli CG, et al; American Society of Clinical Oncology: American Society of Clinical Oncology treatment of unresectable non-small-cell lung cancer guideline: update 2003. J Clin Oncol 22: 330-353,2004.

6. No authors listed: Chemotherapy in non-small cell lung cancer: a meta-analysis using updated data on individual patients from 52 randomised clinical trials. Non-small Cell Lung Cancer Collaborative Group. BMJ 311: 899-909, 1995.

7. Pujol JL, Barlesi F and Daurèsa JP: Should chemotherapy combinations for advanced non-small cell lung cancer be platinum-based? A meta-analysis of phase III randomized trials Lung Cancer 51: 335-345, 2006.
8. Ettinger DS, Bepler G, Bueno R, et al: Non-small cell lung cancer clinical practice guidelines in oncology. J Natl Compr Canc Netw 4: 548-582, 2006.

9. Azzoli CG, Baker S Jr, Temin S, et al; American Society of Clinical Oncology: American Society of Clinical Oncology Clinical Practice Guideline update on chemotherapy for stage IV non-small-cell lung cancer. J Clin Oncol 27: 6251-6266, 2009.

10. Le Chevalier T, Brisgand D, Douillard JY, et al: Randomized study of vinorelbine and cisplatin versus vindesine and cisplatin versus vinorelbine alone in advanced non-small-cell lung cancer: results of a European multicenter trial including 612 patients. J Clin Oncol 12: 360-367, 1994.

11. Fossella F, Pereira JR, von Pawel J, et al: Randomised, multinational phase III study of docetaxel plus platinum combinations versus vinorelbine plus cisplatin for advanced non-small-cell lung cancer: the TAX 326 study group. J Clin Oncol 21: 3016-3024, 2003.

12. Goffin J, Lacchetti C, Ellis PM, et al: First-line systemic chemotherapy in the treatment of advanced non-small cell lung cancer: a systematic review. J Thorac Oncol 5: 260-274, 2010.

13. Jadad AR, Moore RA, Carroll D, et al: Assessing the quality of reports of randomized clinical trials: is blinding necessary? Control Clin Trials 17: 1-12, 1996.

14. Therasse P, Arbuck SG, Eisenhauer EA, et al: New guidelines to evaluate the response to treatment in solid tumors. European Organization for Research and Treatment of Cancer, National Cancer Institute of the United States, National Cancer Institute of Canada. J Natl Cancer Inst 92: 205-216, 2000.

15. Douillard JY, Gervais R, Dabouis G, et al: Sequential two-line strategy for stage IV non-small-cell lung cancer: docetaxel-cisplatin versus vinorelbine-cisplatin followed by cross-over to single-agent docetaxel or vinorelbine at progression: final results of a randomised phase II study. Ann Oncol 16: 81-89, 2005.

16. Cui TJ, Liu ZH, Chen Z, et al: Comparisons among four chemotherapy regimens for advanced non-small cell lung cancer. J Oncol (Chinese) 12: 136-138, 2006.

17. Chen YM, Perng RP, Shih JF, et al: A randomized phase II study of docetaxel or vinorelbine in combination with cisplatin against inoperable, chemo-naïve non-small-cell lung cancer in Taiwan. Lung Cancer 56: 363-369, 2007.

18. Li HM, Li HX, Liu KW, et al: Three chemotherapy regimens including cisplatin for advanced non-small cell lung cancer. J Shandon Univ China (Health Sci) 45: 499-502, 2007.

19. Wang R, Wang YL and Wang QC: A comparison of docetaxel plus cisplatin and vinorelbine plus cisplatin in 67 cases with advanced non-small-cell lung cancer. Bulletin Chin Cancer 16: 476-477, 2007.

20. Song HP, Qiu WS, Xu JH, et al: First-line chemotherapy of docetaxel/cisplatin for advanced non-small cell lung cancer. Chin J Clin Oncol 34: 388-390, 2007.

21. Tan EH, Rolski J, Grodzki T, et al: Global Lung Oncology Branch trial 3 (GLOB3): final results of a randomised multinational phase III study alternating oral and i.v. vinorelbine plus cisplatin versus docetaxel plus cisplatin as first-line treatment of advanced non-small-cell lung cancer. Ann Oncol 20: 1249-1256, 2009.

22. Gebbia V, Lorusso V, Galetta D, et al: First-line cisplatin with docetaxel or vinorelbine in patients with advanced non-small-cell lung cancer: a quality of life directed phase II randomized trial of Gruppo Oncologico Italia Meridionale. Lung Cancer 69: 218-224, 2009.

23. Auperin A, LePechoux C, Pignon JP, et al: Concomitant radio-chemotherapy based on platin compounds in patients with locally advanced non-small cell lung cancer (NSCLC): a meta-analysis of individual data from 1,764 patients. Ann Oncol 17: 473-483, 2006.

24. D'Addario G, Pintilie M, Leighl NB, et al: Platinum-based versus non-platinum-based chemotherapy in advanced non-small-cell lung cancer: a meta-analysis of the published literature. J Clin Oncol 23: 2926-2936, 2005.

25. Lynch TJ, Patel T, Dreisbach L, et al: Cetuximab and first-line taxane/carboplatin chemotherapy in advanced non-small-cell lung cancer: results of the randomized multicenter phase III trial BMS099. J Clin Oncol 28: 911-917, 2010. 